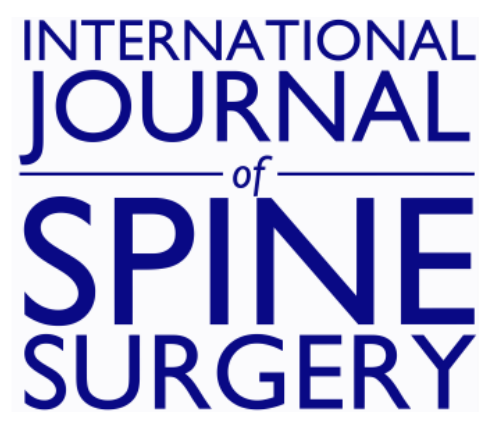

\title{
Prospective Analysis of a New Bone Graft in Lumbar Interbody Fusion: Results of a 2- Year Prospective Clinical and Radiological Study
}

Philippe Lauweryns and Yannic Raskin

Int J Spine Surg 2015, 9 ()

doi: https://doi.org/10.14444/2002

http://ijssurgery.com/content/9/2

This information is current as of April 25, 2023.

Email Alerts Receive free email-alerts when new articles cite this article. Sign up at:

http://ijssurgery.com/alerts

The International Journal of Spine Surgery

2397 Waterbury Circle, Suite 1,

Aurora, IL 60504, Phone: +1-630-375-1432 


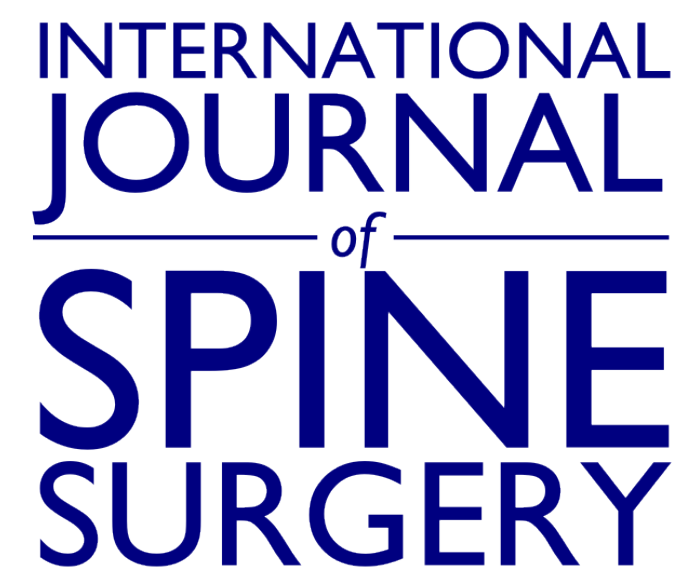

This article generously published free of charge by the International Society for the Advancement of Spine Surgery.

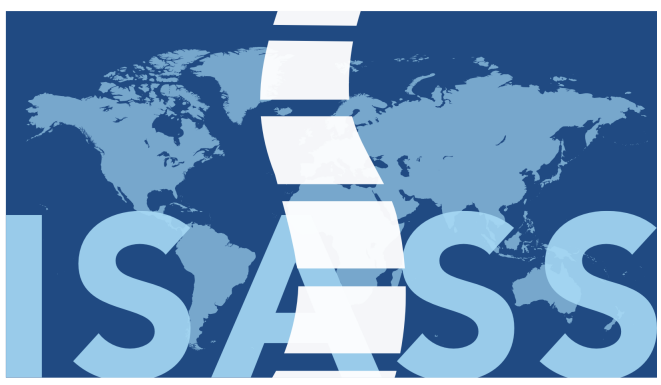

INTERNATIONAL SOCIETY for the ADVANCEMENT of SPINE SURGERY 


\section{Prospective Analysis of a New Bone Graft in Lumbar Interbody Fusion: Results of a 2- Year Prospective Clinical and Radiological Study}

Philippe Lauweryns, $M D$, PhD, Yannic Raskin, $M D$

Orthopaedic Surgery, Sint-Trudo ZiekenHuis, Sint- Truiden, Belgium

\section{Abstract}

\section{Background}

This study examined the efficacy and safety of bone graft material ABM/P-15

(iFACTOR) for use in posterior lumbar interbody fusion. ABM/P-15 has been used safely for more than a decade in dental applications.

\section{Methods}

Forty patients underwent PLIF surgery, with each patient as control. Assessments up to 24 months included radiographs, CT scan, VAS, and ODI. Primary success criteria were fusion and safety.

\section{Results}

Intra-cage bridging bone occurred earlier with ABM/P-15 than autograft $(97.73 \%$ vs. $59.09 \%$ at 6 months). On average pain decreased 29 points and function improved 43 points. Radio dense material outside the disk space occurred more frequently with ABM/ P-15 than autograft, without clinical consequence.

\section{Conclusions}

This study suggests that ABM/P-15 has equal or greater efficacy at 6 and 12 months. Pain improvements exceeded success criteria at all time points. Functional improvement exceeded success criteria at all time points.

\section{Clinical Relevance}

This study explores the safety and efficacy of an osteobiologic peptide enhanced bone graft material as a viable alternative to autograft and its attendant risks. 


\section{Introduction}

Low back pain is common, with a lifetime incidence of $85 \% .{ }^{1}$ When degenerative disease is the cause and unresponsive to conservative therapies, posterior lumbar interbody fusion (PLIF) is an effective surgical technique to address chronic pain. ${ }^{2}$ While autologous bone remains the gold standard for bone graft material in PLIF, associated risks of graft site morbidity ranging up to $25.3 \%$, including chronic pain and other complications, have been well documented. ${ }^{3,4,5}$

There are a variety of bone graft substitutes available. ${ }^{6,7}$ One promising alternative, rhBMP-2, has recently come under increased scrutiny. ${ }^{8,9,10,11,12}$ Clinicians and researchers continue to explore bone graft alternatives that are safe, economical, and comparably effective to autologous bone. This study seeks to add to the dialogue by evaluating the clinical results, safety, and efficacy of a novel osteobiologic peptide enhanced bone graft material (i-FACTOR, Cerapedics Inc., Westminster, Colorado USA) for use in PLIF.

$\mathrm{ABM} / \mathrm{P}-15$ combines anorganic bone mineral (ABM, a natural defect hydroxyapatite) and $\mathrm{P}-15$, a synthetic 15 amino acid polypeptide which acts as an attachment factor for osteogenic cells ${ }^{13,14,15,16,17}$ and which stimulates new bone formation. ${ }^{14,15} \mathrm{ABM} / \mathrm{P}-15$ was originally developed and approved by the FDA for use in dental applications, with demonstrated clinical superiority to both demineralized bone matrix and allograft ${ }^{18,19}$ and a solid safety profile and; it has been in human clinical use in periodontal osseous defects for more than a decade.

This study is the first prospective, controlled, long-term trial performed to date on ABM/ P-15 for use in PLIF. The study hypothesized non-inferiority of ABM/P-15 efficacy and safety compared to autograft for use in PLIF.

\section{Materials and Methods}

\section{Study Design}

Between June 2009 and February 2010, forty patients with varying indications unresponsive to conservative care underwent PLIF surgery with pedicle screw instrumentation performed by an experienced investigator at a single center (Regionaal Ziekenhuis Sint-Trudo, Sint-Truiden, Belgium). The study received ethics committee approval of the Hospital and the University of Antwerp. Patients were screened for eligibility, provided informed consent, and randomized according to birthdate (odd, left; even, right). With the patient as control, each patient received two paired coLigne ostaPek cages (coLigne, Zurich, Switzerland). Local autograft bone was placed inside one cage and $\mathrm{ABM} / \mathrm{P}-15 \mathrm{~B}$ one Graft in the other cage for each vertebral level treated. 
Inclusion criteria were the presence of disc pathology, spinal stenosis, maximum grade 1 isthmic or degenerative spondylolisthesis, and revision of non-union, adjacent level degeneration, or post-discectomy revision between L2 and S1. Patients had to be between 18 to 70 years of age, and psychosocially, mentally, and physically able to comply with the protocol, including follow-up schedules and requirements.

Exclusion criteria were sensitivity to components of the P-15 bone putty, active infection at the operative site, operative site subject to excessive impact or stress, significant vascular impairment proximal to the graft site, use of graft in direct contact with articular spaces, presence of segmental defects, metabolic or systemic bone disorders that affect bone or wound healing, pregnancy/nursing, compromised renal function, compromised immunological system, inability to follow postoperative protocol, history of substance abuse, prisoner, or currently participating in another research project.

VAS scale for back pain and leg pain, Oswestry Disability Index were conducted preoperatively, post-treatment, and at the 3,6,12, and 24 month intervals. Radiographs (3, 6, 12 and 24 months) and CT (6, 12 and 24 month) were used to assess fusion. Two independent, blinded radiologists interpreted all radiographs and CTs. Fusion was evaluated for material within the control (autograft) and study (ABM/P-15) cages. Fusion was defined as an absence of radiolucent lines adjacent to interbody implant and evidence of bridging trabecular bone within the cages. Complications and adverse events were recorded.

\section{Patients}

A total of 40 patients underwent PLIF surgery as part of a lumbar fusion with pedicle screw instrumentation ( 1 to 4 levels). Patient age ranged from 28 to 69 years, with the mean age of 52; 25 were women, 15 were men (Table 1).

\begin{tabular}{|c|c|}
\hline \multicolumn{2}{|l|}{ Patient Demographics } \\
\hline No. of Patients (levels) & $40(45)$ \\
\hline Mean (range) age in years & $52(28-69)$ \\
\hline $\operatorname{Sex}(M / F)$ & $15 / 25$ \\
\hline \multicolumn{2}{|l|}{ BMI } \\
\hline Underweight $(<18.5)$ & $\mathrm{n}=0$ \\
\hline Normal Range (18.5-25) & $\mathrm{n}=16$ \\
\hline Overweight (25-30) & $\mathrm{n}=16$ \\
\hline Obese $(>30)$ & $\mathrm{n}=8$ \\
\hline Tobacco Use (\%) & $11(27.5 \%)$ \\
\hline Diabetes (\%) & $5(12.5 \%)$ \\
\hline Mean (range) follow up period & 24 months \\
\hline
\end{tabular}




\begin{tabular}{|l|l|}
\hline Mean (range) Length of Stay & 5.9 days (5-8) \\
\hline Mean (range) Intra-operative blood loss & $173 \mathrm{cc}(100-300)$ \\
\hline Mean (range) Operation Time & 158 mins (105-300) \\
\hline
\end{tabular}

\section{Surgical Interventions}

Patients were anesthetized, placed in a prone position on a Jackson spinal frame, with extension of the lumbar spine and legs to preserve lumbar lordosis, prepped, and draped. An open posterior interbody lumbar fusion procedure and a partial laminectomy with facetectomies were performed in each patient. The lateral borders of the disc were exposed along with the traversing and exiting nerve roots. Bilateral annulotomies were made, and a complete discectomy was performed through the annular windows. The anterior and lateral walls of the annulus were preserved. Cartilaginous end plates were resected using curettes, and the bony end plates were preserved. Deformities of sagittal and frontal planes were reduced through disc space height restoration and annular tensioning using dilators.

The coLigne ostaPek cages were filled with either ABM/P-15 or morcellized local autograft (Figure 1) from the decompression prior to sequential insertion in the disc space and away from any soft tissue or neural element. Position was assessed intraoperatively with plain radiographs or fluoroscopy. The interbody space surrounding the interbody spacers was packed with remaining local autograft. The fusion was supported with pedicle screw instrumentation.

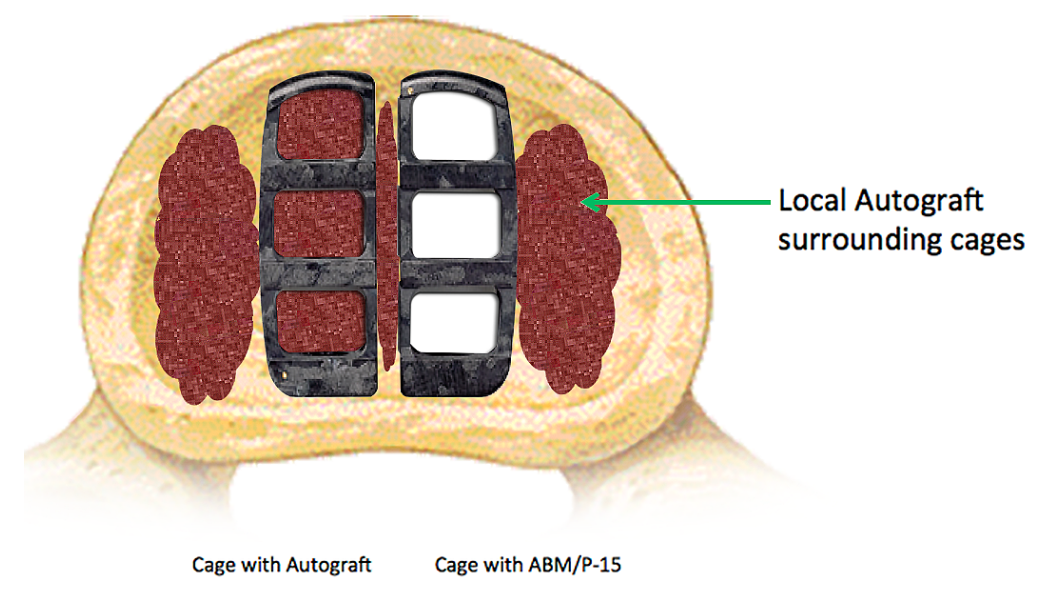

Fig. 1. PLIF Cages/Study Model.

\section{Assessments}

Preoperative baseline data included medical history, physical and neurological examinations, standing A/P and lateral neutral radiograph, and patient-reported outcomes, including Visual Analog Scale (VAS) and Oswestry Disability Index (ODI).

Recorded perioperatively were the amount of ABM/P-15 bone graft administered, surgical procedure levels, blood loss ( $\mathrm{ml})$, and operative time. 
Postoperative data included standing A/P and lateral radiographs (at 3, 6, 12, and 24 months), CT scan (at post-operative pre-discharge, 6, 12, and 24 months, if 12-month CT was inconclusive), neurological evaluation, and patient-reported outcomes including a 100-point VAS for right leg, left leg, and low back pain, and ODI (at 3, 6, 12, and 24 months).

Primary success criteria were fusion and safety (neurological status, operative and postoperative complications, and additional surgery). Fusion success at primary endpoints of 6 months, 12 months and 24 months was determined by radiographic evidence of bridging trabecular bone (within the cages), and absence of radiolucency adjacent to the interbody implants. Fusion was assessed by two independent radiologists according to zone: bridging trabecular bone inside cages, zones 1-3; 4-6 (Figure 2).

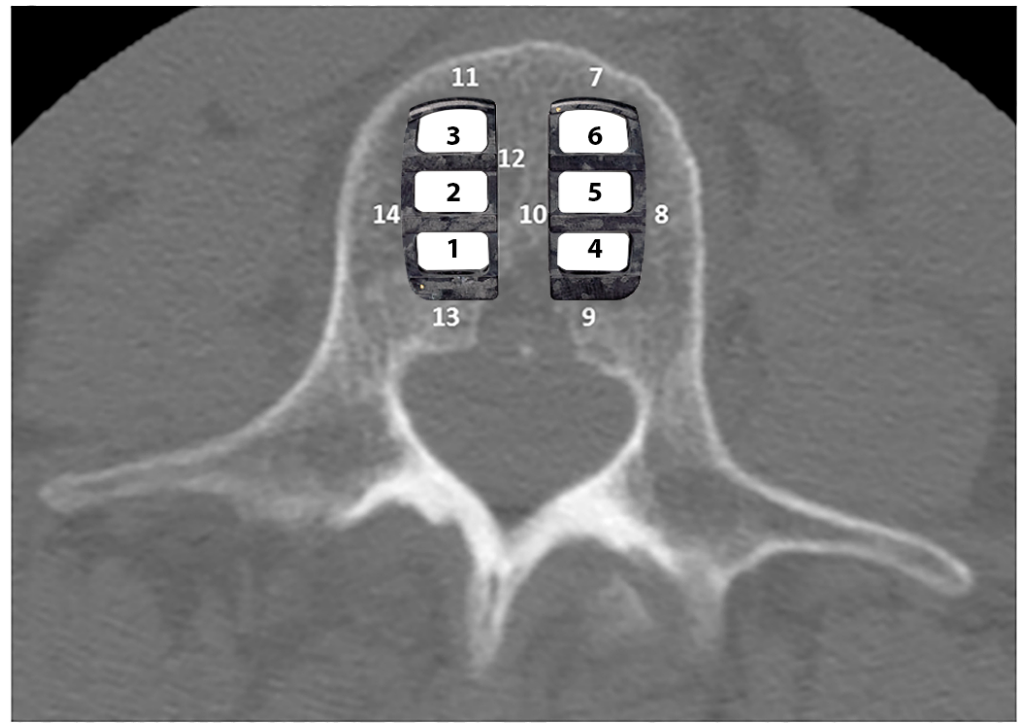

Fig. 2. Intra-cage zones for assessing fusion.

An independent statistician analyzed results. Safety was determined by the proportion of patients with primary endpoints at 6,12 and 24 months who were free from bone-graft or device-related adverse events, without neurologic impairment, and without additional surgery at the operated level(s).

Secondary success criteria were improvement in back pain, right leg/left leg pain, function, and amount and ease of use of $A B M / P-15$. Criteria for pain success was a $\geq 20$ absolute point decrease on the VAS and for function success, $\mathrm{a} \geq 10$ absolute point decrease on the ODI. ${ }^{20,21}$

\section{Statistical Methods}

Statistical analysis was performed by an independent statistician using SAS 9.2 for Windows. Descriptive analyses were performed. Statistical significance was determined using the chi-square and McNemar chi-square test. Each area was analyzed separately (7 comparisons) and 2 composite variables (any bridging bone within the 3 intra-cage areas and any bridging bone at four out-of-the cage areas). 
Though not the focus of this study, in the areas outside the cage there was a difference noted in regard to bridging trabecular bone in the posterior spaces (ABM/P-15 superior to autologous bone) but not in the lateral, medial or anterior spaces. This may have to do with the dispersion of the material during the implantation of the cages.

\section{Results}

A total of 40 patients underwent PLIF surgery as part of a lumbar fusion with pedicle screw fixation. One-level procedures were performed in 24 patients, two-level in 14, and three- and four-level in one patient each, with each vertebral level receiving one cage with local autograft and one cage with ABM/P-15. A total of 45 levels were treated; the most commonly treated levels were L4-L5 - 25 patients (56\%), followed by L5-S1 - 17 (38\%), and L3-L4 - 3 (7\%) (Table 2).

Table 2. Levels treated.
\begin{tabular}{|l|l|l|l|}
\hline No. of levels & No of Patients (\%) & Level & Number(\%) \\
\hline One & $24(60 \%)$ & L2/3 & $0(0 \%)$ \\
\hline Two & $14(35 \%)$ & L3/4 & $3(7 \%)$ \\
\hline Three & $1(2.5 \%)$ & L4/5 & $25(56 \%)$ \\
\hline Four & $1(2.5 \%)$ & L5/S1 & $17(38 \%)$ \\
\hline Total & $40(100 \%)$ & Total & $45(100 \%)$ \\
\hline
\end{tabular}

All 40 patients completed 24-month follow up. Twenty-seven patients (65\%) representing 32 levels ( $71 \%$ levels) elected to not have a CT taken at the 24-month visit but did have radiographs. There was one protocol deviation at 6 months: one $\mathrm{CT}$ scan was not taken at that point.

The presence of intra-cage bridging bone occurred at 6 months in $59.09 \%$ of autograft patients and $97.73 \%$ of $\mathrm{ABM} / \mathrm{P}-15$ patients; at 12 months in $82.22 \%$ of autograft patients and $97.78 \%$ of $\mathrm{ABM} / \mathrm{P}-15$ patients; and at 24 months in $93.33 \%$ of autograft patients and $95.56 \%$ of $\mathrm{ABM} / \mathrm{P}-15$ patients (Table 3). At 24 months, one patient had no bridging bone in the $\mathrm{ABM} / \mathrm{P}-15$ cage but had bridging bone all around the cage. 
Table 3. Presence of bridging bone intra-cage ( $\mathrm{N}=45$ levels).

\begin{tabular}{|l|l|l|l|l|l|l|l|l|l|}
\hline \multicolumn{3}{|c|}{6 months* } & \multicolumn{3}{l|}{12 months } & \multicolumn{3}{l|}{24 months } \\
\hline & Auto & P-15 & P-value** & Auto & P-15 & P-value** & Auto & P-15 & P-value** \\
\hline Anterior & $34.09 \%$ & $70.45 \%$ & $<.01$ & $57.78 \%$ & $88.89 \%$ & $<.01$ & $71.11 \%$ & $88.89 \%$ & n.s. \\
\hline Mid & $43.18 \%$ & $86.36 \%$ & $<.01$ & $73.33 \%$ & $95.56 \%$ & $<.01$ & $80.00 \%$ & $93.33 \%$ & n.s. \\
\hline Posterior & $45.45 \%$ & $68.18 \%$ & n.s. & $73.33 \%$ & $82.22 \%$ & n.s. & $84.44 \%$ & $86.67 \%$ & n.s. \\
\hline Any & $59.09 \%$ & $97.73 \%$ & $<.01$ & $82.22 \%$ & $97.78 \%$ & $<.01$ & $93.33 \%$ & $95.56 \%$ & n.s. \\
\hline Any sign rank test & $1.23 \pm 1.20$ & $2.25 \pm .78$ & $<.01$ & $2.04 \pm 1.14$ & $2.67 \pm .60$ & $<.01$ & & & \\
\hline
\end{tabular}

* $\mathrm{N}=44$ (1 case missing CT); ${ }^{* *}$ McNemar test

$\mathrm{ABM} / \mathrm{P}-15$ is statistically significantly superior to autologous bone in facilitating formation of bridging bone inside the hollow spaces in cage at 6 months with a $\mathrm{P}$-value $<$ .01 and at 12 months with a P-value $<.01$ (Table 3 ). This data suggests that ABM/P-15 is associated with faster formation of bridging bone when compared to autologous bone in patients undergoing PLIF.

Upon radiologic examination, radio dense material was observed outside the disc space posterior to the PLIF cages. ABM/P-15 was observed more frequently than autograft, and both formed bone outside the disc space. Given the concern of bone formation outside the disc space in PLIF, an extensive radiological review and analysis was carried out in an attempt to quantify the frequency and severity of occurrence. A subsequent analysis was also carried out to correlate material outside the disc space to patient outcomes, and if there were any discernible clinical effect on patient outcomes with either ABM/P-15 or autologous bone at all intervals. There was one revision for pseudoarthrosis at 24 months.

Pain improvements, as measured by VAS, exceeded success criteria at all time points. The greatest average decrease in back pain was 43 points $(65.1 \%)$ at 3 months; in left leg pain, a 27-point decrease (55.1\%) at 24-months; and in right leg pain, a 22-point decrease $(57.8 \%)$ at 24 months. VAS leg increased in three of the forty patients post-operatively versus pre-operatively (Table 4, Figure 3).

\begin{tabular}{|c|c|c|c|c|c|c|}
\hline $\mathrm{N}=40$ patients & Preoperative & 3 months & 6 months & 12 months & 24 months & $\%$ gain $2 \mathrm{Yr}$ \\
\hline VAS back pain & 66 & 23 & 42 & 25 & 37 & $29 \%$ \\
\hline VAS left leg & 49 & 25 & 25 & 23 & 22 & $27 \%$ \\
\hline VAS right leg & 38 & 19 & 16 & 18 & 16 & $22 \%$ \\
\hline ODI & 46 & 30 & 18 & 30 & 26 & $20 \%$ \\
\hline
\end{tabular}




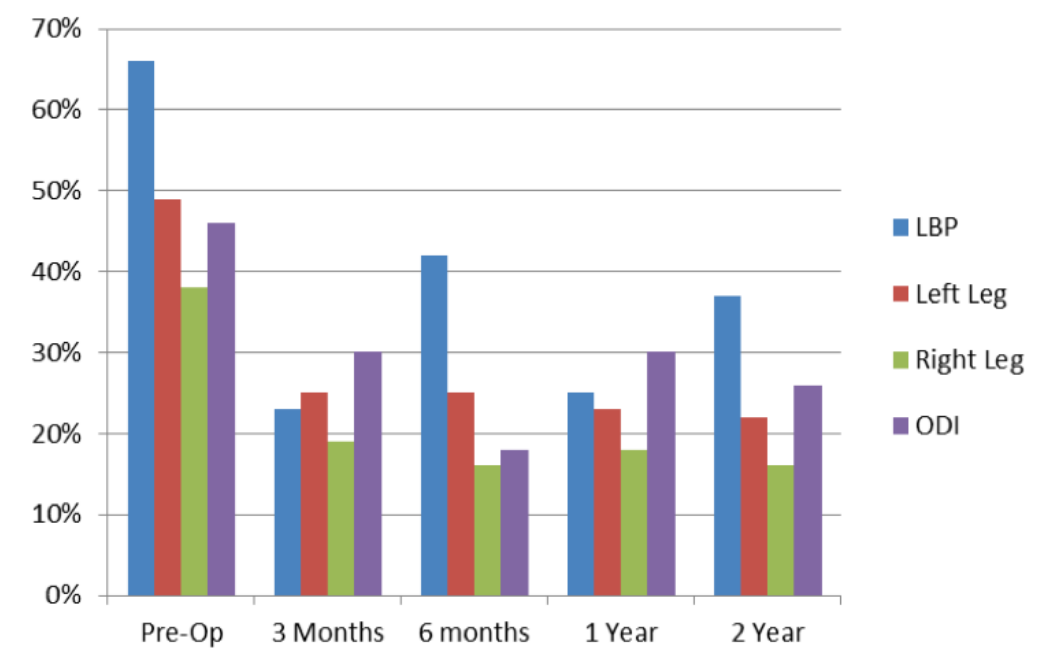

Fig. 3. Patient Outcomes.

Functional improvement, as measured by ODI, exceeded success criteria at all time points, with the greatest improvement in function at 6 months (a 30-point decrease in disability on the 100-percentage-point scale, representing a $60.8 \%$ improvement from baseline), followed by two years (20 point decrease, representing a $43.4 \%$ improvement).

There were no wound problems, no infection, no hematoma, as well as no significant radicular pain problem.

\section{Discussion}

This study represents the first prospective, controlled, long-term study of ABM/P-15and autologous bone for use in PLIF, with 24-month follow-up of participants. The study hypothesized non-inferiority of ABM/P-15 efficacy and safety compared to autograft for use in PLIF. Study results demonstrated ABM/P-15 to be statistically superior to autologous bone in facilitating formation of bridging bone inside the hollow spaces in cages at 6 months $(97.73 \%$ vs. $59.09 \%)$ and at 12 months (97.78\% vs. $82.22 \%)$. At 24 months, ABM/P-15 demonstrated slightly more bone formation than autograft, but not a statistically significant difference $(95.5 \%$ vs. $93.33 \%)$.

Due to the relatively unknown outcomes of $\mathrm{ABM} / \mathrm{P}-15$ for use in PLIF, it was deemed conservative to use both autograft and $\mathrm{ABM} / \mathrm{P}-15$ in each patient at each vertebral level rather than having a separate investigational group at this juncture. This precludes a comparative analysis of and conclusions regarding pain and function-because there is no definitive evidence that pain and function in each leg correlates precisely to left/right vertebral treatment. While clinical improvement was registered, efficacy and safety were the primary end points of the study. It was unexpected to be able to demonstrate clinical difference in such a patient group; therefore, randomization was not integrated into the study design. The study does offer side-by-side comparison of fusion rates, with each patient serving as his or her own control. 


\section{Degree and Timing of Fusion}

The results of this study suggest that use of ABM/P-15 Bone graft in PLIF yields a higher degree of and earlier fusion than autologous bone. ABM/P-15 fusion rates vs. autograft were $97.73 \%$ vs. $59.09 \%$ at 6 months, $97.78 \%$ vs. $82.22 \%$ at 12 months, and $95.56 \%$ vs. and $93.33 \%$ at 24 months, with statistical differences at both 6 and 12 months (Table 3).

\section{Bone Formation Outside the Disc Space}

This study corroborates findings of several other studies that migration of treatment material outside the cage and disc space is a common occurrence. ${ }^{22,23,24,25,26}$ Haid et al. concluded that extra bone formation occurs regardless of bone graft source, and that bone formation after PLIF procedures with stand-alone cages appears to be primarily a radiographic finding only. ${ }^{26}$

In the current study, there was a higher degree of radiographic evidence of ABM/P-15 outside the cages (48\%) than with autograft (14\%). To report our findings, a methodology was established to identify location and severity of material outside the cages. A threedimensional grid was established to report the location of material outside the cages and is represented using an axial view from the lumbar spine (Figure 4).

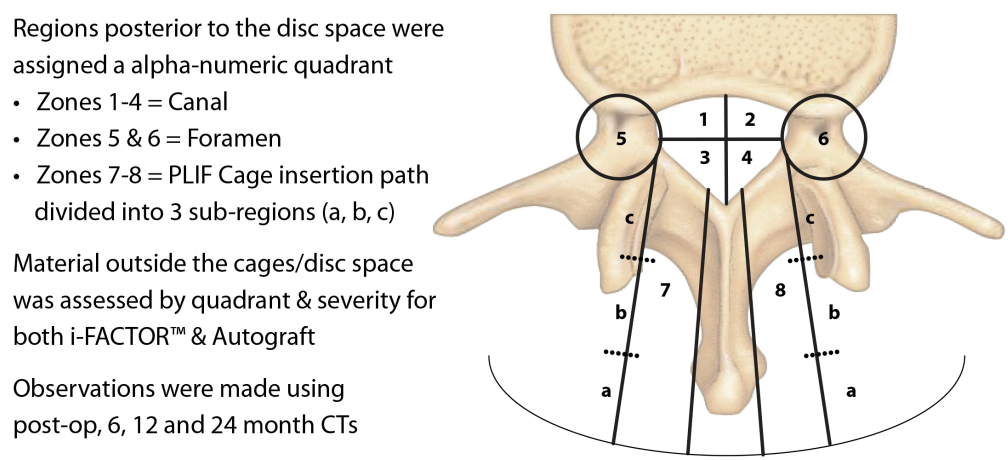

Fig. 4. Radiology analysis/methodology; 40 patients, 45 levels.

Using three-dimensional views from CT scans across all time intervals for all patients, the independent radiologist then reported the location of material outside the cages for both $\mathrm{ABM} / \mathrm{P}-15$ and autograft for all affected levels and for all zones within the grid. For the purpose of reporting the volume and severity of material outside the cages, using radiology viewing software the radiologist drew a region of interest around all 8 zones within the grid. All pixels that are accepted as being less than bone density (Hounsfield units of 500-0) were turned off leaving only the remaining dense pixels which were considered bone. The software program was then used to create a histogram showing how many of the remaining pixels were 0 and how many were over 500. Additionally, the three dimensional volume of the material outside the cages was calculated using the pixel area multiplied by the slice thickness. The radiologist then classified the material outside the cage as minimal (under 50 pixels; less than $0.0129 \mathrm{cc}$ 's of material; barely visible density and most likely would not be called out in a radiology report), mild (50-250 pixels; 0.0129 cc's to 0.0644 cc's of material; visible but not excessive and may be mentioned on a radiology report), and moderate (over 250 pixels; greater than $0.0644 \mathrm{cc}$ 's of material; immediately visible and cause for concern and clearly abnormal). The 
percentage of moderate cases at 24-months was low: $4 \%$ with $\mathrm{ABM} / \mathrm{P}-15$ and $0 \%$ with autograft (Figure 5). All findings were radiographic only and without clinical consequence. The severity of occurrence and size of bone formation decreased over time for both $\mathrm{ABM} / \mathrm{P}-15$ and autograft.

\section{4-Month "MODERATE”}

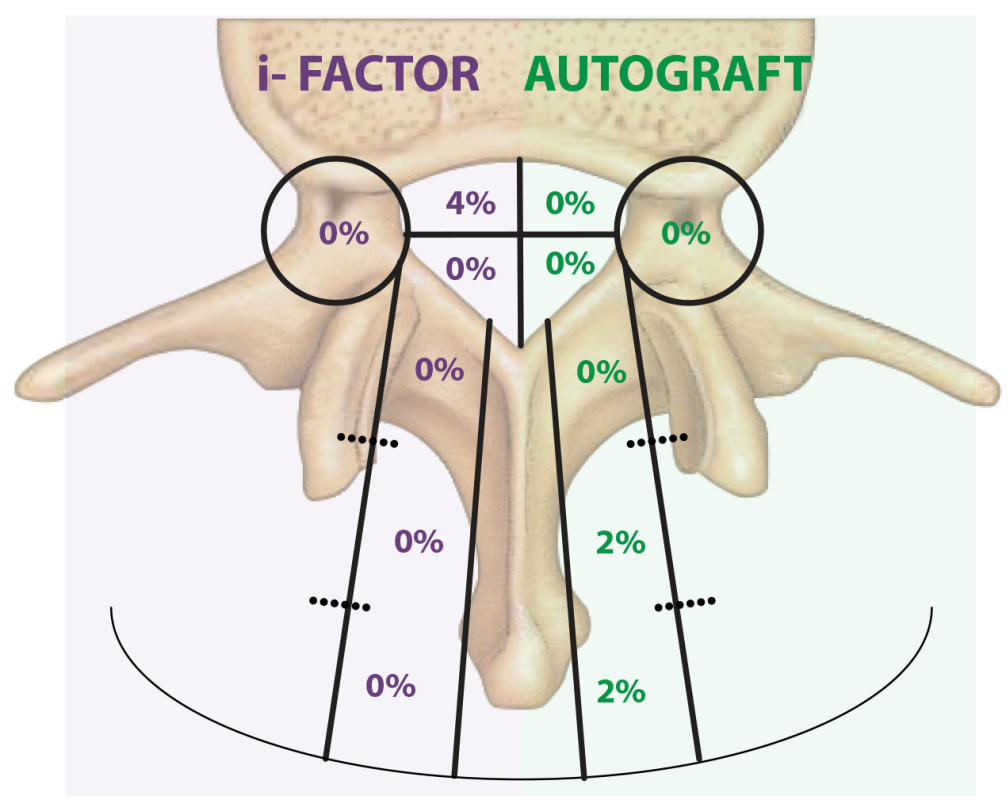

Fig. 5.Occurrence by zone.

Compared to other studies, the current study's occurrence of bone posterior to interbody cages was generally comparable for autograft (13\% in Haid 26 and 8\% in Joseph and Rampersaud 22, vs. $14 \%$ in the current study) and substantially less compared to an alternative bone graft material (75\% with rhBMP2 in Haid 26 vs. $48 \%$ with ABM/P-15 in the current study) (Table 5).

Table 5. Reported occurrence of bone posterior to interbody cages.

\begin{tabular}{|l|l|l|l|l|l|}
\hline \multicolumn{2}{|l|}{ Joseph \& Rampersaud } & \multicolumn{2}{l|}{ Haid, et al $^{26}$} & \multicolumn{2}{l|}{ Lauweryns \& Raskin } \\
\hline rhBMP-2 & Autograft & rhBMP-2 & Autograft & ABM/P-15 & Autograft \\
\hline $\mathrm{n}=23$ & $\mathrm{n}=10$ & $\mathrm{n}=32$ & $\mathrm{n}=31$ & $\mathrm{n}=45$ & $\mathrm{n}=45$ \\
\hline $21 \%$ & $8 \%$ & $75 \%$ & $13 \%$ & $48 \%$ & $14 \%$ \\
\hline & & & & & \\
\hline & & & Minimal & $23 \%$ & $8 \%$ \\
\hline & & & Mild & $22 \%$ & $6 \%$ \\
\hline & & & Moderate & $3 \%$ & $0 \%$ \\
\hline
\end{tabular}




\section{Pain and Function}

Pain reduction and function improvement exceeded the threshold for success at all-time points. Back and leg pain VAS declined a combined average of 29 points from preoperative to the 24-month follow-up (Table 4, Figure 3), exceeding the criterion of $>20$ points reduction defining clinical improvement. Function, as measured by ODI, improved an average of 20 points overall, exceeding the study's criteria of functional success being defined as $>10$ points improvement (Table 4, Figure 3 ). The study's design - with all patients receiving both interventional and control material—prevents comparison of pain and function of $\mathrm{ABM} / \mathrm{P}-15$ with autograft. It might be reasonably deduced, however, that $\mathrm{ABM} / \mathrm{P}-15$ does not have a negative impact on rate of improvement for both pain and function.

\section{Efficacy and Safety of rhBMP-2 vs. Autograft}

There are many bone graft alternatives on the market. ${ }^{6,27,28}$ One with reported outcomes similar to autologous bone is rhBMP-2. ${ }^{29}$ However, some studies suggest complications with its use. A 2008 study $^{30}$ found an association between ectopic bone in the lumbar canal following PLIF/TLIF (transforaminal lumbar interbody fusion) with rhBMP-2 and neurologic impairment in rare cases, challenging a previous publication's ultimate findings of no clinical significance. ${ }^{26}$ Chen et al., (2010) also found symptomatic ectopic bone formation for rhBMP-2 use in TLIF. ${ }^{31}$

Results of a recent, large-scale data analysis entitled Yale University Open Data Access and conducted by the University of York (UK) have rekindled the discussion of rhBMP-2's efficacy and safety. This systematic review and meta-analysis was conducted on full individual participant data with unrestricted independent re-analysis of studies comparing rhBMP-2 to iliac crest bone graft. It examined the potential benefits and harms of rhBMP-2 and assessed the reliability of the heretofore published evidence. The review found no significant evidence that rhBMP-2 is more effective than autograft in inducing spinal fusion. It also found that rhBMP-2 is associated with increased early post-operative pain and an unsubstantiated potential small, short-term increased risk of cancer. The incidence of complications in spinal surgery in general was found to be similar between autograft and rhBMP-2, but rhBMP-2 appeared to increase the rate of complications in anterior cervical surgery and increased the rate of ectopic bone formation in PLIF (which was thought to be associated with neurologic complications). The review also found some evidence of reporting bias - a substantial proportion of outcomes collected in trials were not reported. Adverse effects were found to be incompletely and inadequately described, with $23 \%$ of all adverse events that were collected in randomized, controlled studies actually reported in publications. ${ }^{8,9,10,11}$

\section{Efficacy and Safety of ABM/P-15 vs. Autograft}

The results of this study confirm the overall efficacy and safety of both materials in PLIF. For both materials, none of the device-related adverse events were serious. Migration of material is an expected technical event that occurs during PLIF and rarely causes clinical symptoms. $^{22,26}$ 
Findings suggest that ABM/P-15 has equal or greater efficacy than autologous bone in PLIF at 6 and 12 months with statistical significance and equivalence at 24 months. This study provides independent radiographic evidence as well as self-reported outcomes from patients. Patients in the study experienced a statistically higher degree of fusion earlier (at 6 and 12 months) with ABM/P-15 than with autograft. Pain and function improvements met or exceeded success criteria at all time points.

Study strengths include that it is a long-term, prospective, controlled study. Both graft materials were subjected to the exact same conditions and comorbidities, reducing extraneous factors influencing fusion outcomes. Of the 13 participants (32.5\%) with no CT imaging performed/available at 24-month time point, $100 \%$ were fused according to $\mathrm{CT}$, having achieved intra-cage bridging bone at the 12-month time; all 13 had 24-month radiographs. The study also provided side-by-side comparison of the fusion rate for $\mathrm{ABM} / \mathrm{P}-15$ and autologous bone, with each patient serving as a control.

Study limitations include the small sample size and lack of a separate control group, which does not offer as "clean" a comparison as two separate patient groups. We cannot rule out the potential for "biological crosstalk," with either autograft or ABM/P-15 migrating and benefitting the other. To reduce the risk of any occurrence influencing interpretation of outcomes, we had an independent radiologist report fusion only inside each of the cages.

Additional studies - with separate interventional and control groups and larger sample sizes - are needed to further investigate and clearly delineate differences between the efficacy and safety of ABM/P-15 and autograft.

\section{Key Points}

- $\mathrm{ABM} / \mathrm{P}-15$ is statistically significantly superior to autologous bone in facilitating formation of bridging bone inside the hollow spaces in cages at 6 months and at 12 months.

- $\mathrm{ABM} / \mathrm{P}-15$ is associated with faster formation of bridging bone when compared to autologous bone in patients undergoing PLIF. ABM/P-15 showed a higher incidence of graft migration than autograft.

- Migration and heterotopic ossification did not cause any clinical symptoms for either ABM/P-15 or autograft.

- There are alternatives to iliac crest bone graft, including ABM/P-15, that are equally or more effective in the formation of bridging bone.

\section{Acknowledgments}

This study was supported via a grant from Cerapedics, Inc., Westminster, Colorado USA.

\section{References}

1. Spoor AB, Oner FC. Minimally invasive spine surgery in chronic low back pain patients. J Neurosurg Sci. 2013;57(3):203-218.

2. Costa F, Sassi M, Ortolina A, Cardia A, Assietti R, Zerbi A, Lorenzetti M, Galbusera F, Fornari M. Stand-alone cage for posterior lumbar interbody fusion in the treatment 
of high-degree degenerative disc disease: design of a new device for an "old" technique. A prospective study on a series of 116 patients. Eur Spine J. 2011;20 Suppl 1:S46-56. Available from: http://www.ncbi.nlm.nih.gov/pmc/articles/ PMC3087031/.

3. Sawin PD, Traynelis VC, Menezes AH. A comparative analysis of fusion rates and donor-site morbidity for autogeneic rib and iliac crest bone grafts in posterior cervical fusions. J Neurosurg. 1998;88(2):255-65.

4. Burkus JK, Gornet MF, Dickman CA, Zdeblick TA. Anterior lumbar interbody fusion using rhBMP-2 with tapered interbody cages. J Spinal Disord Tech. 2002; 15:337-49.

5. Dimitriou R, Mataliotakis GI, Angoules AG, Kanakaris NK, Giannoudis PV. Complications following autologous bone graft harvesting from the iliac crest and using the RIA: a systematic review. Injury. 2011;42 Suppl 2:S3-15. doi: 10.1016/ j.injury.2011.06.015

6. DeLong, WG Jr, Einhorn TA, Koval K, McKee M, Smith W, Sanders R and Watson T. Bone grafts and bone graft substitutes in orthopaedic trauma surgery. A critical analysis. J Bone Joint Surg Am. 2007;89:649-58.

7. Abdullah KG, Steinmetz MP, Benzel EC, Mroz TE The state of lumbar fusion extenders. Spine (Phila Pa 1976). 2011;15;36(20):E1328-34. doi: 10.1097/ BRS.0b013e318209952b

8. Simmonds MC, Brown JV, Heirs MK, Higgins JP, Mannion RJ, Rodgers MA, Stewart LA. Safety and effectiveness of recombinant human bone morphogenetic protein-2 for spinal fusion: a meta-analysis of individual-participant data. Ann Intern Med. 2013;158(12):877-89.

9. Rodgers MA, Brown JV, Heirs MK, Higgins JP, Mannion RJ, Simmonds MC, Stewart LA. Reporting of industry funded study outcome data: comparison of confidential and published data on the safety and effectiveness of rhBMP-2 for spinal fusion. BMJ. 2013;346:f3981.

10. Fu R, Selph S, McDonagh M, Peterson K, Tiwari A, Chou R, Helfand, M. Effectiveness and harms of recombinant human bone morphogenetic protein-2 in spine fusion: a systematic review and aeta-analysis. Ann Intern Med. 2013;158(12):890-902.

11. Resnick D, Bozic KJ. Meta-analysis of trials of recombinant human bone morphogenetic protein-2: What should spine surgeons and their patients do with this information? Ann Intern Med. 2013;158(12):912-13.

12. Carragee EJ, Hurwitz EL, Weiner BK. A critical review of recombinant human bone morphogenetic protein-2 trials in spinal surgery: emerging safety concerns and lessons learned. Spine J. 2011;11(6):471-91.

13. Sherman BP, Lindley EM, Turner AS, Seim HB 3rd, Benedict J, Burger EL, Patel VV. Evaluation of ABM/P-15 versus autogenous bone in an ovine lumbar interbody fusion model. Eur Spine J. 2010;19(12):2156-63.

14. Gomar F, Orozco R, Villar JL, Arrizabalaga F. P-15 small peptide bone graft substitute in the treatment of non-unions and delayed union. A pilot clinical trial. Int Orthop. 2007;31(1):93-99.

15. Yang, XB, Bhatnager RS, Li S, Oreffo, ROC. Biomimetic collagen scaffolds for human bone cell growth and differentiation. Tissue Eng. 2004; 10 (7-8):1148-59. 
16. Qian JJ, Bhatnagar RS. Enhanced cell attachment to anorganic bone mineral in the presence of a synthetic peptide related to collagen. J Biomed Materials Res. 1996;31(4):545-54.

17. Bhatnagar RS, Qian JJ, Gough CA. The role in cell binding of a beta-bend within the triple helical region in collagen alpha 1 (I) chain: structural and biological evidence for conformational tautomerism on fiber surface. J Biomol Struct Dyn. 1997;14(5):547-60.

18. Yukna RA, Callan DP, Krauser JT, Evans GH, Aichelmann-Reidy ME, Moore K, et al. Multi-center clinical evaluation of combination anorganic bovine bone-derived hydroxyapatite matrix (ABM)/cell-binding peptide (P-15) and ABM in human periodontal osseous defects: 6-month results. J Periodontol. 1998;69:655-63.

19. Yukna RA, Krauser JT, Callan DP, Evans GH, Cruz R, Martin M. Multi-center clinical comparison of combination anorganic bovine bone-derived hydroxyapatite matrix (ABM)/cell-binding peptide (P-15) and ABM in human periodontal osseous defects: 6-month results. J Periodontol. 2000;71(11):1671-79.

20. Haag O, Fritzell P, Nordwall A. The clinical importance of changes in outcomes scores after treatment for chronic low back pain. Eur Spine J. 2003;12(1):12-20.

21. Ostelo RW, Costa LO, Maher CG, de Vet HC, van Tulder MW. Rehabilitation after lumbar disk surgery. Cochrane Database Syst Rev. 2008;(4)CD003007. doi: 10.1002/ 14651858.CD003007.pub2.

22. Joseph V, Rampersaud YR. Heterotopic bone formation with the use of rhBMP2 in posterior minimal access interbody fusion. A CT analysis. Spine (Phila Pa 1976). 2007;32(25):2885-90.

23. Kim SU, Yang TK, Lee JC, MD. Radiological changes in the bone fusion site after posterior lumbar interbody fusion using carbon cages impacted with laminar bone chips: follow-up study over more than 4 years. Spine (Phila Pa 1976). 2005;30(6):655-60.

24. Brower RS, Vickroy NM. A case of psoas ossification from the use of BMP-2 for posterolateral fusion at L4-L5. Spine (Phila Pa 1976). 2008;33(18):E653-55.

25. Glassman SD, Howard JM, Sweet A, Carreon LY. Complications and concerns with osteobiologics for spine fusion in clinical practice. Spine (Phila $\mathrm{Pa} 1976$ ) 2010;35(17):1621-28.

26. Haid RW, Branch CL Jr, Alexander JT, Burkus JK. Posterior lumbar interbody fusion using recombinant human bone morphogenetic protein type 2 with cylindrical interbody cages. Spine J. 2004;4(5):527-38.

27. Mobbs RJ, Loganathan A, Yeung V, Rao PJ. Indications for anterior lumbar interbody fusion. Orthop Surg. 2013;5(3):153-63.

28. Brandoff JF, Silber JS, Vaccaro AR. Contemporary alternatives to synthetic bone grafts for spine surgery. Am J Orthop. 2008;37(8):410-14.

29. Boden SD, Zdeblick TA, Sandhu HS, Heim SE. The use of rhBMP-2 in interbody fusion cages. Definitive evidence of osteoinduction in humans: a preliminary report. Spine (Phila Pa 1976). 2000;25(3):376-81.

30. Wong DA, Kumar A, Jatana S, Ghiselli G, Wong K. Neurologic impairment from ectopic bone in the lumbar canal: a potential complication of off-label PLIF/TLIF use of bone morphogenetic protein-2 (BMP-2). Spine J. 2008;8(6):1011-18.

31. Chen NF, Smith ZA, Stiner E, Armin S, Sheikh H, Khoo LT. Symptomatic ectopic bone formation after off-label use of recombinant human bone morphogenetic 
protein-2 in transforaminal lumbar interbody fusion. J Neurosurg Spine. 2010;12(1):40-46.

\section{Disclosures}

This study was supported via a grant from Cerapedics, Inc., Westminster, Colorado USA.

\section{Corresponding Author}

Philippe Lauweryns, MD, PhD, Orthopaedic Surgery, Sint-Trudo ZiekenHuis, Diestersteenweg 100, 3800 Sint-Truiden Belgium. Philippe.Lauweryns@stzh.be

Published 3 February 2015.

Copyright (C) 2015 ISASS - International Society for the Advancement of Spine Surgery. To see more or order reprints or permissions, see http://ijssurgery.com. 